\title{
Direct Endoscopic Necrosectomy: Timing and Technique
}

\author{
Sergio Pinto ${ }^{1, *(\mathbb{D}}$, Saverio Bellizzi $\left.{ }^{2} \mathbb{(}\right)$, Roberta Badas ${ }^{1}$, Maria Laura Canfora ${ }^{1}$, Erica Loddo ${ }^{1} \mathbb{C}$, Simone Spada ${ }^{1}$, \\ Kareem Khalaf $^{3}{ }^{-}$, Alessandro Fugazza ${ }^{4}$ and Silvio Bergamini ${ }^{1}$
}

1 Digestive Endoscopy Unit, Department of Surgical Sciences, University Hospital of Cagliari, 09042 Cagliari, Italy; rbadas@aoucagliari.it (R.B.); mcanfora@aoucagliari.it (M.L.C.); ery.loddo@gmail.com (E.L.); s.spada@aoucagliari.it (S.S.); s.bergamini@aoucagliari.it (S.B.)

2 Medical Epidemiologist, Independent Consultant, 1202 Geneva, Switzerland; saverio.bellizzi@gmail.com

3 Department of Biomedical Sciences, Humanitas University, Pieve Emanuele, 20090 Milano, Italy; kareem.khalaf@st.hunimed.eu

4 Digestive Endoscopy Unit, Department of Gastroenterology, Humanitas Research Hospital-IRCCS, 20089 Rozzano, Italy; alessandro.fugazza@humanitas.it

* Correspondence: sergiopinto.dr@gmail.com; Tel.: +39-07051096423

check for updates

Citation: Pinto, S.; Bellizzi, S.; Badas,

R.; Canfora, M.L.; Loddo, E.; Spada,

S.; Khalaf, K.; Fugazza, A.; Bergamini, S. Direct Endoscopic Necrosectomy: Timing and Technique. Medicina 2021, 57, 1305. https://doi.org/10.3390/ medicina57121305

Academic Editor: Andrea Anderloni

Received: 18 October 2021

Accepted: 24 November 2021

Published: 28 November 2021

Publisher's Note: MDPI stays neutral with regard to jurisdictional claims in published maps and institutional affiliations.

\begin{abstract}
Walled-off pancreatic necrosis (WOPN) is one of the local complications of acute pancreatitis (AP). Several interventional techniques have been developed over the last few years. The purpose of this narrative review is to explore such methodologies, with specific focus on endoscopic drainage and direct endoscopic necrosectomy (DEN), through evaluation of their indications and timing for intervention. Findings indicated how, after the introduction of lumen-apposing metal stents (LAMS), DEN is becoming the favorite technique to treat WOPN, especially when large solid debris or infection are present. Additionally, DEN is associated with a lower adverse events rate and hospital stay, and with improved clinical outcome.
\end{abstract}

Keywords: walled-off pancreatic necrosis; pancreatic necrotic collection; acute pancreatitis; direct endoscopic necrosectomy; EUS; LAMS

\section{Introduction}

Acute pancreatitis (AP) represents one of the most common gastroenterological disorders requiring hospitalization [1,2].

Most cases of AP undergo an uncomplicated course, where supportive care with intravenous fluid infusion, nutritional support, analgesic therapy, and accurate monitoring suffice to achieve a full recovery [2,3]. Yadav and Lowenfels reported a worldwide incidence of AP between 13 and 45 cases per 100,000 persons per year [4].

According to the 2012 revised Atlanta classification and definitions [1], AP can be subdivided in two types, which based on its appearance on contrast-enhanced computed tomography (CECT) [5]. The first is interstitial oedematous pancreatitis, which is the most common type, characterized by diffuse or localized pancreatic and peripancreatic inflammatory oedema, and necrotizing pancreatitis (5-10\% of AP cases), characterized by the presence of pancreatic $(<5 \%)$ or peripancreatic necrosis (about $20 \%$ ). The second is both pancreatic and peripancreatic necrosis (75-80\%) [6]; the aforementioned features an increased mortality rate up to $32 \%$ when a superimposed infection occurs, which happens in about one third of these patients [3,7]. Pancreatic fluid collections (PFCs), develop as local complications of AP in about $20 \%$ of cases [8].

Depending on the type of AP, PFCs can contain liquid or necrotic material, and are classified as either:

Acute peripancreatic fluid collections (APFCs): are retroperitoneal extra-pancreatic collections confined by the normal fascial planes, without a defined wall, which occurs in interstitial oedematous acute pancreatitis [1]. 
Pancreatic pseudocysts (PPCs): are retroperitoneal peripancreatic or, occasionally, intrapancreatic fluid collections, confined by a defined wall composed of granulation tissue, fibrous tissue, and blood vessels, which contain homogeneous sterile amylase rich fluid with no solid debris and which also occur in interstitial oedematous acute pancreatitis [1,9].

Acute necrotic collections (ANCs): are pancreatic and/or peripancreatic collections of inhomogeneous fluid and necrotic material, without a defined wall [9]. They may be multiple and multiloculated and arise within the first 4 weeks of acute necrotizing pancreatitis (ANP) from the liquefaction of solid necrotic areas. ANCs may gradually resolve spontaneously, get infected (30\% of cases) or evolve into walled-off necrosis $[5,10]$.

Walled-off pancreatic necrosis (WOPN): are pancreatic and/or peripancreatic collections of necrotic tissue, which arise from the maturation of ANCs. Within approximately 2-4 weeks or more, a capsule made of granulation tissue and collagen forms. This might be a natural defense against the spreading of pancreatic enzymes, inflammation, and necrosis, which are contained by the fibrous wall [11,12]. It may be single or multiple and carries a higher risk of infection $[9,13]$.

Due to their higher morbidity and mortality, pancreatic necrotic collections (PNCs) need to be promptly recognized and adequately treated [14]. Therefore, distinguishing between a necrotic and a fluid collection is crucial to guarantee the best outcome for the patient. Differentiating between a PPC and a WOPN may not always be obvious under CECT; MRI and endoscopic ultrasonography (EUS) evaluation are better tools to identify solid debris inside the collection (Figure 1) [1,15].

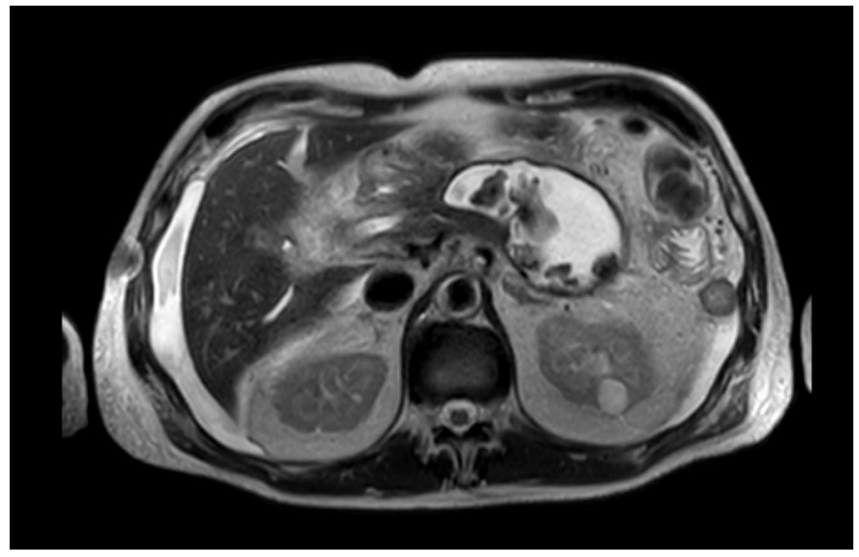

Figure 1. MRI image of a WOPN with both liquid and solid necrotic material within.

\subsection{Indication for Intervention in PNCS}

In about half of the WOPN cases, patients are completely asymptomatic; whilst the other half may be burdened with malaise, abdominal pain, anorexia, weight loss, relapsing or recurrent pancreatitis, fever (in case of infection), compression or erosion and fistulization in the adjacent structures (stomach, blood vessels, bile duct) $[11,16,17]$. According to the current international guidelines, WOPN requires intervention only when patients become infected, such as the case of persistent organ failure or failure to thrive, or the case of adjacent organ compression or persistent symptoms, even if it's sterile $[2,13,14]$.

Infection complicates about $30 \%$ of ANP cases and is associated with an increased mortality rate (up to $32 \%$, versus $10 \%$ of sterile ANP) [3,7,13], requiring a prompt diagnosis to organize an appropriate therapeutical strategy. A combination between clinical signs (fever, bacteriemia, worsening leukocytosis, new/prolonged organ failure, increasing or elevated CRP and procalcitonin levels), radiological signs (gas bubbles in a necrotic collection at the CECT), fine needle aspiration (FNA) and subsequent GRAM stain or culture, seems to be the best strategy to diagnose ANP. Gas bubbles are seen at CECT in only half of the patients with ANP, and FNA has a false negative rate of $29 \%[12,17]$. Thus, routine FNA of the necrotic collection is not advised and it may be performed in case of 
no benefit from the initial antibiotic therapy, or when clinical and radiological signs are unclear [14,17].

There is no evidence to support a broad spectrum intravenous antibiotic prophylaxis for the prevention of infection in ANP [2]. Such therapy should be started only when infection is suspected; for this purpose, carbapenems, quinolones, metronidazole, and third- or higher-generation cephalosporins showed a good penetration in the pancreatic and peripancreatic tissue $[2,13]$. Since less than $5 \%$ of patients with infected pancreatic necrosis recover with antibiotic therapy alone, it is almost always an indication for invasive intervention [12].

\subsection{Evolution of Interventional Techniques: From the Operating Theatre to the Endoscopic Room, a Target Approach}

Many interventional strategies have been proposed to treat PNCs. Over the years we assisted to a gradual transition from traditional open surgery to minimally invasive surgery and endoscopic interventions.

The current international guidelines suggest adopting the so called "step-up approach" indicating a gradual increase from a less invasive to a more invasive procedure, when needed $[2,13,14]$. This concept may seem obvious and reasonable, but many studies were necessary to reach such an agreement, and more are still needed to further define the best way to treat PNCs. Furthermore, considering the broad diversity of each PNC (anatomical site, number, dimension, percentage of solid debris, infection, involvement of contiguous structures, amount of defined wall and its thickness, presence of wall blood vessels) together with the diversity of the clinical condition of each patient, trying to find a single technique to treat all the PNCs, may be unreasonable. In this scenario, targeting the best procedure for each patient is crucial. Until 2010, the standard approach to symptomatic or infected PNC was open surgery: laparotomic debridement of the necrotic tissue and subsequent placement of drainage and lavage tubes [14]. In order to reduce mortality, risk of iatrogenic infection and systemic inflammation, intervention should be postponed for 4 weeks after the onset of symptoms, allowing enough time for the collection to be completely encapsulated (i.e., WOPN) [18,19]. Despite such precautional measures, open necrosectomy is associated with a high rate of local and systemic complications (35 to 95\%) and death (11 to 39\%) [20-22]. Therefore, with the evolution of technology and techniques, new strategies of intervention have been evaluated to reach better outcomes.

The PANTER trial published in 2010, represents a milestone for the WOPN surgical treatment [22]. Van Santvoort et al. demonstrated that a minimally invasive step-up surgical approach (percutaneous drainage followed, if necessary, by a video-assisted retroperitoneal debridement (VARD), and subsequent lavage of the cavity through percutaneous drainage) on patients with infected WOPN was superior to open necrosectomy in terms of new onset organ failure and diabetes, necessity of ICU admission, incisional hernias and total cost, with similar mortality rate [22].

In line with this minimally invasive approach, endoscopists started performing drainage of PFCs through the stomach or duodenal wall.

The first pioneering direct endoscopic necrosectomy (DEN) was described in 2000 by Seifert et al. on three patients with infected WOPN, not fit enough for a surgical intervention [23]. They inserted a gastroscope directly into the cavity and performed the debridement of the necrotic material using a stone-retrieval basket.

The term "direct" refers to the access to the necrotic collection gained directly by the endoscope through the gastric or duodenal wall, allowing visualization and removal of necrotic debris [24]. Small DEN series, conducted mainly in Europe, showed encouraging results in infected and symptomatic WOPN [25-28].

In order to assess DEN efficacy, complications and mortality rate, Seifert et al. carried a large retrospective multicenter study with long-term follow-up (the GEPARD study) [24]. A sample of 93 patients with infected WOPN containing $>50 \%$ of solid debris on ultrasonography or EUS, underwent DEN after a mean of 41 days (4-158) after AP onset. A mean of 6.2 DEN sessions (1-35) were conducted every 1-4 days until all debris and necrotic 
material were removed. A minimum of 2 years follow-up (clinical, laboratory and imaging) was conducted, showing an initial success rate of $81 \%$, a long-term clinical efficacy rate of $68 \%$, a complication rate of $26 \%$ and a procedure-related mortality rate of $7.5 \%$ [24].

A study by Gardner et al. on 104 patients with infected or symptomatic WOPN reached even better clinical outcomes than the GEPARD study [29]. Resolution of the collection was achieved in $91.3 \%$ of patients, with a periprocedural adverse events (AEs) rate of $14 \%$ and a mortality rate of $5.7 \%$.

It seemed clear that DEN was a feasible and less invasive alternative to surgery for treating WOPN. However, lack of comparative trials made it difficult to definitely assess the real effectiveness and safety of the DEN compared to other techniques. A multicenter randomized controlled trial (the PENGUIN trial [30]) conducted by Bakker et al. attempted to fill that gap. They compared the proinflammatory response and the clinical outcome between DEN and surgical necrosectomy (VARD or open, preceded by percutaneous drainage of the collection) in patients with infected WOPN [30]. According to their results, DEN was associated with significantly lower IL-6 levels (which is a pro-inflammatory cytokine) and lower rate of complications ( $20 \%$ vs. $80 \%)$.

The Dutch Pancreatitis Study Group conducted a randomized trial (the TENSION trial) to investigate whether an endoscopic step-up approach (EUS-assisted transgastric or transduodenal placement of two double pigtail stents and a nasocystic catheter; if no clinical improvement was achieved, one or more DEN was performed) was superior to the surgical step-up approach (CT-guided or ultrasound-guided percutaneous catheter drainage; if no clinical improvement was succeeded, a VARD procedure was performed) in patients with infected pancreatic collection [31]. Despite comparable results in terms of major complications and mortality rates between the two groups, cardiovascular and persistent cardiovascular organ failure were lower in the endoscopy group, as was the incidence of pancreatic fistulas (with subsequent increase in hospital stay and follow up evaluation), number of drainage catheter repositionings and hospital stay. Moreover, in 2018, a pooled analysis conducted on 1980 severely ill patients with ANP who underwent necrosectomy, found that minimally invasive surgical necrosectomy and DEN were associated with reduced death rates compared with open necrosectomy [21].

Two recent meta-analyses independently conducted by Bang et al. and Haney et al. [32,33] on the same three randomized trials involving 184 patients with infected WOPN [30,31,34], compared clinical outcomes of minimally invasive surgical intervention and endoscopic intervention. Endoscopic intervention was associated with less new onset organ failure, enterocutaneous fistula or perforation of a visceral organ, pancreatic fistula and shorter hospital/ICU stay.

Another recent meta-analysis conducted by Khan et al. [35] on two randomized trials and four observational studies, involving 641 patients with infected or symptomatic WOPN compared safety and clinical outcomes of minimally invasive surgical intervention to endoscopic intervention. Endoscopic intervention was associated with lower mortality, less new onset organ failure, enterocutaneous fistula or perforation of a visceral organ, pancreatic fistula and shorter hospital/ICU stay.

These studies combined suggest that an endoscopic step-up approach, when possible, is the most advisable procedure to treat patients with infected WOPN in order to reduce complications and mortality rates, hospital stay and total costs. If the necrotic collection is not reachable endoscopically (when involving one or both the paracolic gutters and/or the pelvis) or if the endoscopic approach is not available or unsuccessful, a mini-invasive surgical step-up approach is recommended $[2,13,14]$.

\subsection{Endoscopic Step-Up Approach}

The aim of an endoscopic intervention on symptomatic or infected WOPN is to gain access to the collection and perform a transmural drainage of the content into the gastric/duodenal lumen, using plastic or metal stents. Necrosectomy may be performed using the already finished fistulas and, depending on the kind of stent used, through the stent itself. 


\subsubsection{Double Pigtail Plastic Stent Drainage}

Drainage can be obtained by EUS-guided single or multiple cystenterostomy, positioning one (single transluminal gateway technique, STGT) or more (multiple transluminal gateway technique, MTGT) double pigtail plastic stents (DPPs) through the stomas [13,36]. MTGT, firstly performed by Varadarajulu et al. in 2011, should be used as a first step on those patients with multiple or large $(>12 \mathrm{~cm})$ WOPN, where a STGT may be ineffective, or as a second step after suboptimal drainage with previous STGT [13,36]. Data about WOPN resolution with DPPS drainage alone, show a clinical success between $30.8 \%$ and $52.1 \%[31,36,37]$.

\subsubsection{Fully Covered Self-Expandable Metal Stents}

DPPSs are notoriously cheap and widely diffused; but their small 7-10 F caliber does not allow a good drainage of the larger solid necrotic debris, with frequent stent lumen occlusion. Moreover, they require multiple stent placement and dilation procedures to obtain a cystoenterostomy of caliber wide enough to perform DEN [38]. Fully covered selfexpandable metal stents (FCSEMSs) represented the first alternative to DPPSs. Their larger diameter allows better drainage of solid debris, with lower rates of occlusion [9,37-39].

Biliary stents are successfully used to drain PFCs; however, their small diameter is not sufficient to avoid the occlusion of the lumen by solid necrotic material and does not allow passage of the endoscope to perform DEN through the stent itself $[9,13,38]$. Esophageal FCSEMSs have been first used to treat WOPN endoscopically in 2009 by Antillon et al., who successfully treated a patient with infected WOPN after four inefficacious DEN sessions, demonstrating that the use of a $22 \mathrm{~mm}$ FCSEMS with intensive lavage may be an effective option to facilitate WOPN drainage in selected patients [40]. Sarkaria et al. reported their experience with 18-23 mm esophageal FCSEMSs on 17 patients with infected WOPN, with an overall success rate of $83 \%$, a faster stent deployment compared to DPPS, and no need to replace the stent between each session [38].

The main AEs using FCSEMS are: stent migration, bleeding from the fistulous tract, stent migration and injury of the duodenal/gastric wall or of the retroperitoneum, resulting in bleeding and/or perforation $[9,41]$.

\subsubsection{Lumen-Apposing Metals Stents (LAMSs) \\ Technical Aspects of LAMSs}

To overcome DPPS and FCSEMS limitations, in 2011 a different kind of SEMS was developed, namely lumen apposing metal stent (LAMS) [42]. The AXIOS stent (Boston Scientific, Marlborough, MA, USA) was the first LAMS commercialized. It is made of braided nitinol, fully covered with silicone, with a dog bone shape given by two bilateral double-walled anchoring flanges with a $90^{\circ}$ angle between each flange and the narrower central part of the stent. Its design should prevent stent migration, allowing the apposition of the walls of two luminal structures, putting them in communication and preventing leakage from the fistula. Its delivery method consists of a multistep EUS-guided procedure: using a through-the-scope device (compatible with therapeutic echoendoscopes with a $\geq 3.7$-mm working channel) [43].

After the creation of a fistula between the two luminal structures by needle plus guidewire and its dilation with a pneumatic balloon over a guidewire, the LAMS is progressively deployed [42]. After AXIOS introduction, different manufacturers produced different kinds of LAMSs and SEMS with anti-migratory systems with different features and delivery mechanisms (Spaxus and Nagi, by Taewoong Medical, Gimposi, Korea; Aixstent, by Leufen Medical, Berlin, Germany; Hanarostent Plumber, by M.I. Tech, Pyeongtaek-si, Korea) [44,45].

An evolution of this device was introduced in 2015 by Boston Scientific: an electrocauteryLAMS (EC-LAMS) (HOT-AXIOS, Boston Scientific, Marlborough, MA, USA). This represents a second-generation device, implemented with a cautery tip for the fistula creation. The new 
system simplifies the delivery of the LAMS by immediate one-step procedure, without the need of an access for needle plus guidewire, or further dilation of the fistula [41].

The EC-LAMS is available in many different diameters and lengths to better adapt to anatomical sites $(6 \times 8 \mathrm{~mm}, 8 \times 8 \mathrm{~mm}, 10 \times 10 \mathrm{~mm}, 15 \times 10 \mathrm{~mm}, 15 \times 15 \mathrm{~mm}$, and $20 \times 10 \mathrm{~mm}$ ). Their larger diameter and shorter length, together with the peculiar shape and the delivery system, should provide a better drainage of necrotic solid debris, reducing the risk of migration, perforation, and intra-operative and post-operative bleeding [46-49]. Furthermore, it allows access through its lumen to the WOPN by an endoscope to perform DEN (Figure 2).

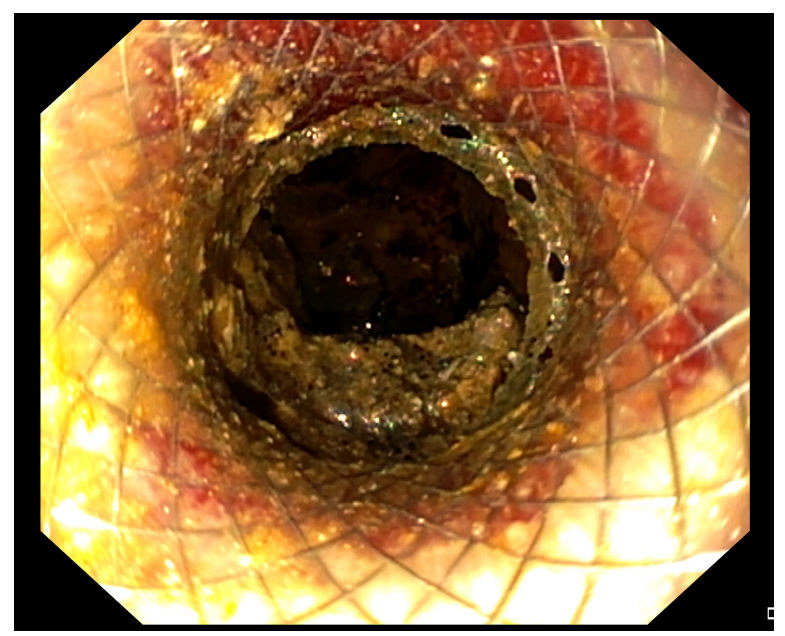

Figure 2. Endoscopic view of a WOPN cavity through the lumen of the LAMS, draining necrotic material.

\section{Clinical Practice with LAMSs}

After LAMS diffusion, many studies have been conducted in the attempt to assess its efficacy, safety, and AEs rate in WOPN treatment.

Both LAMS and EC-LAMS have shown high technical (95-100\%) and clinical (84.2-93.9\%) success rates $[43,44,47-49]$. Sharahia et al. reported a WOPN resolution after only drainage in $27.1 \%$ with symptomatic WOPN using a single 10 or $15 \mathrm{~mm}$, showing a higher clinical success with the bigger LAMS [43].

Similarly, comparing the 15- and 20-mm EC-LAMS, Parsa et al. reported that fewer DEN sessions are needed to reach WOPN resolution when using the $20 \mathrm{~mm}$ EC-LAMS [44] and Bekkali et al. found that the use of EC-LAMS was associated with a reduced procedure time when compared with a first-generation LAMS in drainage and DEN [50]. Binda et al. demonstrated how MTGT can also be safely and efficaciously carried out with EC-LAMS for treating complex WOPN [50].

In our clinical practice we usually place a large LAMS (15 or $20 \mathrm{~mm}$ in diameter) depending on the amount of necrotising of the WOPN. After LAMS deployment we dilate the stent with a pneumatic balloon to check its contents, the amount of necrosis and the presence of vessels. The large diameter of the LAMS facilitates drainage of necrotic contents leading to faster resolution of the collection. For this reason, DEN could be avoided in case of symptoms improvement. Then, a follow-up CECT scan to verify treatment response is organized at 3 weeks, followed by LAMS removal in case of WOPN resolution, as suggested by Bang et al. [51].

The overall LAMS-related AEs rate treating WOPN appears difficult to evaluate because of the lack of data uniformity among published series. The main AEs reported are migration/dislodgement of the stent (2.6-10.6\%), occlusion (0.9-8.7\%), bleeding (0.7-5.5\%) and perforation (0-1.3\%) [39].

Dislodgement of the LAMS, in particular during DEN, could be resolved with the replacement of the same stent [52]. 
On the contrary, bleeding and perforation are life threatening and challenging AEs, since they can involve both the enteric and the retroperitoneal wall. As previously mentioned, the higher diameter of LAMSs and its shorter length, compared to the dimensions of the other stents, should reduce the risk of bleeding both from the fistula (by compressing surrounding wall vessels) and from the enteric and retroperitoneal wall (due to its reduced protruding portion).

While this seems true for the fistular bleeding, this may not be correct for the retroperitoneal bleeding. During a comparative trial with EC-LAMS and DPPSs, Bang et al. noticed that a higher than anticipated procedural AEs rate occurred in the LAMS group ( $50 \%$ vs. $0 \%$ [51]. The AEs included bleeding, buried stent syndrome and obstructive jaundice secondary to stent-induced biliary stricture. Since all of the AEs appeared after 3 weeks from LAMS positioning, authors hypothesized that the wide caliber of the stent may lead to a fast resolution of the WOPN with subsequent collapse of the wall of the collection and friction against the distal flange of the LAMS, and subsequent erosion, perforation, and bleeding (including pseudoaneurysm bleeding). For the same reason, since the LAMS is immobile through the gastric/duodenal wall, it can become deeply buried into the wall itself, leading to the "buried stent syndrome" or to fibrotic reaction involving adjacent structures, like the common bile duct. Thus, authors suggest performing a CT scan in 3 weeks, followed by removal of the LAMS if the WOPN has resolved [51]. Therefore, early LAMS removal after 4 weeks is becoming a widely suggested practice to avoid late AEs [53].

Data reported by Fugazza et al. on a large international cohort of 304 patients that underwent drainage of PFCs with LAMS, show how about $60 \%$ of bleeding episodes occurred in the first 14 days after LAMS positioning, raising attention to the fact that LAMS-related bleeding cannot be considered exclusively as a late $\mathrm{AE}$ (no protective role of EC-LAMS was observed for bleeding or other AEs) [54]. Furthermore, they showed how the pneumatic dilation of the LAMS after deployment reduces the risk of AEs.

\subsubsection{Comparing DPPSs with LAMS}

These studies suggest that both LAMS and EC-LAMS are safe devices, with high technical and clinical success rates in WOPN treatment. The debate about safety and efficacy of the LAMS compared to the DPPS is still a controversial topic among the scientific community.

A recent systematic review and meta-analysis conducted on 30 studies with 1524 patients with WOPN, tried to solve such doubts [39]. Despite the already mentioned difficulty to perform such analysis because of the lack of uniformity in outcome definitions and reporting across studies, they found a similar AEs rate (bleeding, perforation, stent migration and stent occlusion) and similar efficacy rate between the two devices. Chen et al. conducted a cost-effectiveness analysis comparing LAMSs with DPPSs in the management of WOPN, reporting that, despite a higher cost of LAMSs, their higher efficacy ( $92 \%$ vs. $84 \%)$ makes this device more cost-effective [55].

\subsubsection{Endoscopic Gastric Fenestration (EGF)}

With the purpose to overcome disadvantages of DPPs and LAMS for the therapy of WOPN (small caliber and poor drainage, occlusion of the stent, bleeding, migration, jaundice, and high cost) Liu et al. have recently explored a different modality to gain access to the necrotic collection, the endoscopic gastric fenestration (EGF) [56]. For the feasibility of the procedure, a complete evaluation of the characteristics of the collection with CECT and EUS is performed, as a close adherence between the gastric and the collection wall is mandatory to proceed. Total intravenous anesthesia and tracheal intubation are performed. EUS guidance guarantees to find and mark the best site on the gastric wall to perform a fenestration by endoscopic submucosal dissection (ESD), until the muscularis propria and the wall of the collection are penetrated. Subsequent enlargement of the fenestration is carried out $(1.5-3 \mathrm{~cm})$ and a nasocystic catheter may be positioned to irrigate the cavity during the 
following hours/days. Drainage and DEN are performed and CT and endoscopic follow up is performed. EGF was performed in 5 patients: one failed because of nonadherence between the gastric and cystic wall, while the other four patients had a rapid resolution of the WOPN within 3 weeks, with self-healing of the fenestration.

This novel technique seems promising for those collection adherents to the gastric wall; however, further studies, with a higher number of patients involved, are required to validate the EGD and better assess efficacy, costs, AEs, and long-term outcomes.

\section{Technical Aspects}

The first preliminary step to perform DEN is the localization of the most appropriate site to practice the cystoenterostomy (usually posterior gastric or median duodenal wall) [57]. This should always be conducted under EUS assistance, since it allows one to evaluate the extent of the collection, the amount of solid vs. liquid material, thickness of the wall, and the presence of interposed structures and blood vessels (using the Doppler flow guidance) $[13,41,58]$. In addition, if needed, it allows one to perform FNA with subsequent culture or GRAM stain, and to inject contrast to visualize the cavity under fluoroscopy $[13,41,59]$. The next step is different, depending on the kind of stent used:

- DPPS: with a needle assisted procedure, a guidewire is advanced under fluoroscopic guidance and dilation of the tract is performed with an $\geq 8 \mathrm{~mm}$ pneumatic balloon $[29,30]$. Two or more DPPSs of 7-10 F are positioned, in order to keep the stoma open for maturation and drain the content of the collection. Furthermore, using multiple DPPSs reduces the probability of stent occlusion and migration [30,31]. Subsequent dilations with balloons of increasing diameter $(15-20 \mathrm{~mm})$ are performed to obtain a cystoenterostomy of caliber big enough to advance the endoscope inside the cavity and perform the DEN. If there is a need to keep the cystoenterostomy open, multiple DPPSs are placed [23,30].

- LAMS: with a needle assisted procedure, a guidewire is advanced under fluoroscopic guidance and a dilation of the tract is performed with a $4-10 \mathrm{~mm}$ pneumatic balloon to facilitate the advancement of the LAMS delivery catheter over the wire. The distal flange is deployed under EUS guidance, traction is then applied to appose the distal flange against the cyst wall and bring it in firm apposition against the stomach/duodenal wall. The proximal flange was then deployed under endoscopic guidance [42] or with the intra-channel release technique [60].

- $\quad$ EC-LAMS: the deployment catheter is positioned on the selected point on the gastric/duodenal wall. The activation of the electro-cautery tip allows direct passage of the catheter into the collection under EUS guidance. The distal flange of the LAMS is deployed, and the next steps are the same as the LAMS (Figure 3) [50].

Since the use of air instead of $\mathrm{CO}_{2}$ for insufflation is a well-known cause of gas embolism during DEN, current international guidelines advice to avoid air insufflation when performing DEN $[13,29,61]$. In fact, after its introduction in DEN practice, no gas embolism events have been reported [13].

After performing DEN, a nasocystic catheter can be placed in parallel or through the stents to cautiously flush the collection with saline or hydrogen peroxide, avoiding forced injection of high fluid volumes, which may cause rupture of the cavity wall with fatal consequences $[13,30,62,63]$. 


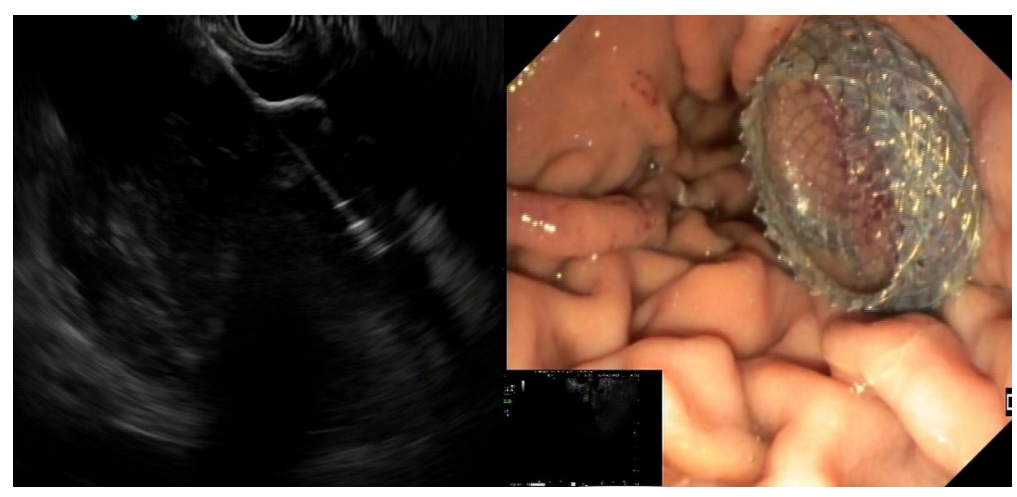

Figure 3. EUS image of the distal flange of an EC-LAMS deployed into a WOPN (left) and endoscopic view of the proximal flange after positioning the EC-LAMS (right).

\section{Devices}

After entering the collection, the fluids and little necrotic debris are sucked through the endoscope working channel. The bigger necrotic debris and those adherent to the wall are grabbed with various devices conceived for other purposes, like polypectomy snares (Figure 4), Dormia basket, Roth basket, other stone removal baskets and forceps of various shape (grasping, tripod, rat-tooth, pelican), and released into the stomach/duodenum [13,23-25,37,41,64]. In 2018 Van Der Wiel et al. reported the first two cases of WOPN treated with a novel device, the EndoRotor Powered Endoscopic Debridement (PED) System ${ }^{\circledR}$ (Interscope Medical, Inc., Worcester, MA, USA) [65].

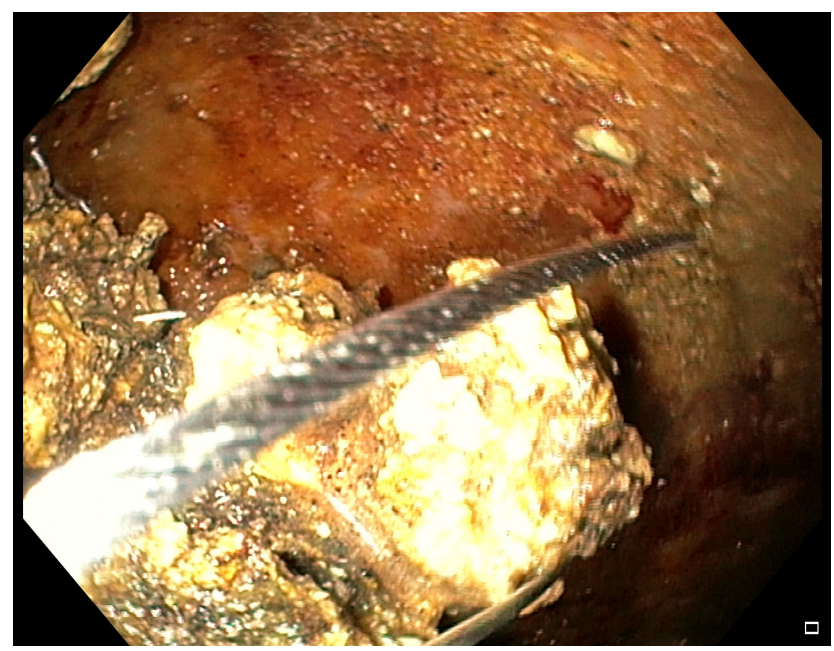

Figure 4. Endoscopic view of a WOPN cavity during a DEN session, where necrotic debris are grabbed with a polypectomy snare.

The EndoRotor ${ }^{\circledR}$ is a through-the scope tool designed for use in the gastrointestinal tract for tissue dissection and resection, later modified to perform safely and efficaciously DEN. The instrument passes through a working channel of at least $3.2 \mathrm{~mm}$ and has a fixed outer cannula with a hollow inner cannula that rotates at either 1000 or 1700 revolutions per minute, as set up in the electronic control console, cutting 2-4 $\mathrm{mm}$ of tissue per second [65-67]. The inner cannula has an opening through which a 50-550 $\mathrm{mmHg}$ negative pressure allows one to collect the cut tissue into a trap or into a standard vacuum container; both the rotating and the suction function are controlled by the operator with two separate foot pedals [66-68].

After two small series by Van Der Wiel et al. [67] and Larghi et al. [68], reporting a successful use of the EndoRotor ${ }^{\circledR}$ to perform DEN, Stassen et al. conducted the first 
multicenter prospective trial involving 30 patients with symptomatic WOPN requiring DEN, whose results were recently published on the Gastrointestinal Endoscopy Journal [69]. They reported a median number of 1.5 EndoRotor ${ }^{\circledR}$-assisted DENs required to achieve an average reduction of $85 \%$ in collection volume and $91 \%$ of necrotic debris. Three DENrelated AEs occurred ( $10 \%$ of patients), but none of them was classified as EndoRotor ${ }^{\circledR}$ related (two cases of stent-related bleeding, and one case of pneumoperitoneum due to the endoscope being torqued within the LAMS), with a mortality rate of $3 \%$.

In each series authors expressed a positive opinion, especially about the short learning curve required to easily manipulate the tool, the possibility to constantly visualize the operating area with a low estimated risk of causing complications, and the fact that no repeated retrieval and insertion of the endoscope are needed to perform the necrosectomy $[65,67,68]$.

These data suggest that the EndoRotor ${ }^{\circledR}$ may be an effective and safe dedicated device to perform DEN, but further studies are required to confront classical and EndoRotor ${ }^{\circledR}$. assisted DEN.

\section{Irrigation}

Hydrogen peroxide $\left(\mathrm{H}_{2} \mathrm{O}_{2}\right)$ is a colorless liquid which rapidly dissociates into oxygen and $\mathrm{H}_{2} \mathrm{O}$ when in contact with organic tissues, producing a soft foam that helps removing materials attached to the tissue, including necrotic debris [70,71]. Furthermore, it seems help wounds healing by stimulating granulation and fibrosis [72]. In order to use its healing and chemical debridement properties, it has often been used as aid in DEN, despite lack of properly designed clinical trials to assess its efficacy, AEs, and technical aspects in such field [62].

For this reasons, current international guidelines suggest restraint regarding $\mathrm{H}_{2} \mathrm{O}_{2}$ assisted DEN $[13,14]$. Many series and comparative trials, published both prior to and after the publication of the guidelines, reported a high technical and clinical success of $\mathrm{H}_{2} \mathrm{O}_{2}$ assisted DEN, a reduced number and duration of DEN sessions, with sometimes no need at all for mechanical debridement, and an AEs profile and rate similar to non- $\mathrm{H}_{2} \mathrm{O}_{2}$-assisted DEN [70,72-74].

Such results were confirmed by a recent systematic review and meta-analysis by Garg et al. conducted on 15 studies involving a total of 454 patients who underwent $\mathrm{H}_{2} \mathrm{O}_{2}$ assisted DEN (median concentration 3\%, range $0.1-3 \%$ with dilution and volume 1:1-1:10 and $20 \mathrm{~mL}$ to $1 \mathrm{~L}$ respectively) [71]. Their analysis reported a high technical and clinical success rate $(97.3 \%$ and $89.8 \%$ respectively), with an AEs rate of $17.9 \%$ (bleeding, stent migration, and perforation), comparable to DEN performed without $\mathrm{H}_{2} \mathrm{O}_{2}$.

Several cases of gas embolism have been reported after $\mathrm{H}_{2} \mathrm{O}_{2}$ use in neurosurgery, orthopedic surgery, fistula irrigation and wound debridement [75-80]. This potentially lethal $\mathrm{AE}$ may be due to the rapid and high amount of free oxygen released after the contact with organic tissue (the breakdown of $20 \mathrm{~mL}$ of $3 \% \mathrm{H}_{2} \mathrm{O}_{2}$ solution releases $200 \mathrm{~mL}$ of gaseous oxygen) [81]. To the best of our knowledge no case of such $\mathrm{AE}$ has been reported in the published $\mathrm{H}_{2} \mathrm{O}_{2}$-assisted DEN series. Some authors suggest that $\mathrm{H}_{2} \mathrm{O}_{2}$-induced gas embolism may be favored by its use into closed and semi-closed cavities, where oxygen release may cause an increase of the cavity pressure, facilitating gas passage into blood vessels $[72,82]$. Low flow saline irrigation may be a safer alternative practice to help performing DEN.

\section{Vacuum Assisted Closure System}

It is worth mentioning that in the literature there are a few reports of the successful use of an endoscopic vacuum-assisted therapy (EVAT) and the Endo-SPONGE (B. Braun, Melsungen, Germany) for facilitating infected WOPN healing after drainage and DEN [83-87]. The combined action of the Endo-SPONGE (which absorbs inflammatory fluids and induces tissue granulation), together with the negative pressure (which drains inflammatory fluids, increases vascularization and cell proliferation), should lead to a faster and easier resolution of the WOPN [86-88]. On the other hand, this procedure is not abhorrent from 
risks, as highlighted by Wallstabe et al. [84]. Performing EVAT in an area rich of important vascular structures such as the region of the celiac trunk and portal venous system carries, in theory, a higher risk of bleeding then performing the therapy in other body regions [89]. As outlined in the current guidelines, the amount of series of EVAT applied to WOPN is still too small to make this technique a standard of care for PNCs [13]. Furthermore, no randomized controlled trials have been performed yet and the potential AEs profile has not yet been established.

\section{Timing}

Timing of intervention in PNCs is still a hot topic among the scientific community. Postponing any invasive intervention until the PNC has walled-off is a surgery practice heritage, which has its roots in the increased mortality and complication rate after early open necrosectomy [18,89-91]. Current international guidelines advise to delay any invasive intervention until at least 4 weeks after the AP onset [2]. This seems a wise approach for those patients stable enough to wait for the collection to be walled-off, but emerging data are showing that early intervention is possible and advisable for patients with clinical deterioration despite maximum support [13,14,92].

A recent survey by van Grinsven et al. reported a lack of consensus among experts regarding timing and usefulness of early PNC intervention (both drainage and necrosectomy), showing that early intervention is already incorporated into clinical practice [93]. Van Grinsven et al. conducted a randomized controlled trial (POINTER trial) with the aim of better understanding whether immediate step-up approach (endoscopic or surgical) in patients with INP is superior to postponed step-up approach with regard to clinical outcome and cost-effectiveness [19]. Results were presented at the 2020 UEG week, showing no difference between the two strategies in mortality, new onset organ failure, major complications and hospital stay. Trikudanathan et al. conducted a study on 193 patients with ANP treated with endoscopic step-up approach and/or percutaneous catheter drainage when needed [92]. Interventions were categorized as early if timing of intervention was $<4$ weeks (76 patients), and standard if $\geq 4$ weeks from onset of AP. They reported an increased in mortality rate ( $14 \%$ vs. $4 \%)$, need for rescue open necrosectomy, hospital and ICU stay in the "early intervention" group, with similar improvement in organ failure and similar complication rate. Albers et al. treated 49 patients with confirmed or suspected IPN with STGT or MTGT with LAMS (15 mm diameter $\times 10 \mathrm{~mm}$ length or 16 $\mathrm{mm}$ diameter $\times 20 \mathrm{~mm}$ length) after a median of seven days after the first proof of necrosis, when most of the necrotic collections were not expected to be encapsulated [12]. DEN was always performed during the same procedure, except for patients with sepsis, where DEN was performed post-recovery. They reported a $100 \%$ technical success, an $87.8 \%$ clinical success, and an $8.2 \%$ mortality rate, in line with previous studies and meta-analysis $(5.7-14.5 \%)[24,29,32,57]$.

This study also confirms results of a previous series by Yan et al., who wanted to compare the typical strategy of delaying DEN after LAMS placement (1 week), allowing maturation of the cystoenterostomy, with performing DEN immediately after LAMS positioning [58]. They found that performing DEN at the time of initial stent placement is safe, effective, and leads to an earlier WOPN clinical resolution, with similar AEs rate.

\section{Conclusions}

Symptomatic and infected necrotic collections still represent challenging and lifethreatening complications of AP. Many steps have been performed after minimally invasive interventional techniques showed the first results and became available in daily clinical practice.

An endoscopic step-up approach has been proven to be, when applicable, an effective way to minimize invasiveness during interventions, reducing complications, mortality, hospital stay and total costs. When endoscopic drainage is not sufficient to gain a clinical improvement and resolution of the necrotic collection, DEN is advised in order to remove 
both the liquid and solid necrotic material from the collection, facilitating the healing process. When endoscopic expertise is not available, or the necrotic collection is not endoscopically reachable (when involving the paracolic gutters and/or the pelvis), or when the endoscopic approach failed to gain resolution of the necrotic collection, a surgery step-up approach is recommended [13,14].

In the last decade, many innovations and many studies allowed endoscopists to reach huge results. Diffusion of LAMS and EC-LAMS helped to simplify endoscopic maneuvers. They can be easily placed with a single step deployment platform, allowing one to effectively and safely drain necrotic collections, and immediately gain access to the cavity within a few moves. Furthermore, the availability of LAMS of different caliber (up to $20 \mathrm{~mm}$ ), allows one to adapt the treatment to the characteristics of the wall and the content of the collection, even when composed of solid necrotic material [49]. Recent trials also demonstrated how the apposition of multiple stents in different sites, especially when dealing with large and multiloculated PNCs, facilitates the drainage of the collections, even though using LAMS reduces the need to use the MTGT when compared to PSs [50]. A recent cost-effectiveness analysis also showed how, despite being more expensive, LAMSs are more cost-effective compared to PSs [55]. Evidence, together with our experience gained over the years in collaboration with several international centers, led us to widely prefer using LAMSs over PSs for treatment of WOPN, and we think that they will be the most preferred option for end treatment of PNCs in the long term. Furthermore, in the validation of the Orlando Protocol [94], Bang et al. reported a success rate of $94.1 \%$ treating WOPN using LAMSs, compared to $84.3 \%$ using PSs.

Even if safe and effective, classical DEN is a time-consuming technique that requires multiple passages through the fistulous tract to grab necrotic debris and release them into the stomach or duodenal lumen. The EndoRotor ${ }^{\circledR}$, a novel specifically designed throughthe scope tool, allows one to perform DEN maintaining the endoscope into the cavity while cutting and sucking necrotic debris with the device itself, making DEN quicker and safer. An interventional randomized clinical trial is still ongoing (NCT04814693) with the purpose to better assess efficacy and safety of this device, also compared to conventional DEN [95]. New approaches and interventional techniques, like the EVAT, are under validation to reach always better technical and clinical outcomes. Clinical practice and trials showed how critical patients may benefit of an early intervention, cautiously overcoming old guidelines.

These results are drawing a path for the management of PNCs that will lead clinicians to a target approach, sewing the treatment directly on the characteristics of each patient and its disease. Hopefully, with the tremendous technological progress we are facing, in the near future newer tools and techniques will be developed. More techniques, more strategies, and more devices, mean a wider choice to reach better outcomes, reducing morbidity, mortality, and total costs, improving working conditions, and general wellbeing of the patients. In light of these rapid changes, the so-called "endoscopic step-up approach" for the treatment of WOPN is not to be intended as a linear process to follow step by step, but is more like a branched-out path where the clinical response leads to a wide range of different options about when and how to intervene. Availability of medical expertise, medical devices, and the latest medical updates will lead clinicians to the choice of the best treatment strategy possible.

More studies and more trials must take place in order to better assess what should be or become clinical daily practice, and what should be relegated to the past, as outdated by more recent data.

Author Contributions: Conceptualization, S.P., R.B., M.L.C., E.L., S.S. and S.B. (Saverio Bellizzi); methodology, S.P., S.B. (Silvio Bergamini) and A.F.; writing — original draft preparation, S.P.; writingreview and editing, S.P., S.B. (Saverio Bellizzi), K.K. and A.F.; supervision, A.F. and S.B. (Silvio Bergamini). All authors have read and agreed to the published version of the manuscript.

Funding: This research received no external funding.

Institutional Review Board Statement: Not applicable. 
Informed Consent Statement: Not applicable.

Conflicts of Interest: The authors declare no conflict of interest.

\section{References}

1. Banks, P.A.; Bollen, T.L.; Dervenis, C.; Gooszen, H.G.; Johnson, C.D.; Sarr, M.G.; Tsiotos, G.G.; Vege, S.S.; Windsor, J.A.; Horvath, K.D.; et al. Classification of Acute Pancreatitis-2012: Revision of the Atlanta Classification and Definitions by International Consensus. Gut 2013, 62, 102-111. [CrossRef]

2. Working Group IAP/APA. Acute Pancreatitis. IAP/APA Evidence-Based Guidelines for the Management of Acute Pancreatitis. Pancreatology 2013, 13 (Suppl. S2), 1-15. [CrossRef] [PubMed]

3. Trikudanathan, G.; Wolbrink, D.R.J.; van Santvoort, H.C.; Mallery, S.; Freeman, M.; Besselink, M.G. Current Concepts in Severe Acute and Necrotizing Pancreatitis: An Evidence-Based Approach. Gastroenterology 2019, 156, 1994-2007. [CrossRef] [PubMed]

4. Yadav, D.; Lowenfels, A.B. The Epidemiology of Pancreatitis and Pancreatic Cancer. Gastroenterology 2013, 144, 1252-1261. [CrossRef]

5. Dhaka, N.; Samanta, J.; Kochhar, S.; Kalra, N.; Appasani, S.; Manrai, M.; Kochhar, R. Pancreatic Fluid Collections: What Is the Ideal Imaging Technique? World J. Gastroenterol. 2015, 21, 13403-13410. [CrossRef] [PubMed]

6. Wang, M.; Wei, A.; Guo, Q.; Zhang, Z.; Lu, H.; Li, A.; Hu, W. Clinical Outcomes of Combined Necrotizing Pancreatitis versus Extrapancreatic Necrosis Alone. Pancreatology 2016, 16, 57-65. [CrossRef]

7. Petrov, M.S.; Shanbhag, S.; Chakraborty, M.; Phillips, A.R.J.; Windsor, J.A. Organ Failure and Infection of Pancreatic Necrosis as Determinants of Mortality in Patients with Acute Pancreatitis. Gastroenterology 2010, 139, 813-820. [CrossRef]

8. DiMaio, C.J. Management of Complications of Acute Pancreatitis. Curr. Opin. Gastroenterol. 2018, 34, 336-342. [CrossRef]

9. Umapathy, C.; Gajendran, M.; Mann, R.; Boregowda, U.; Theethira, T.; Elhanafi, S.; Perisetti, A.; Goyal, H.; Saligram, S. Pancreatic Fluid Collections: Clinical Manifestations, Diagnostic Evaluation and Management. Disease-a-Month 2020, 66, 100986. [CrossRef]

10. Van Brunschot, S.; Bakker, O.J.; Besselink, M.G.; Bollen, T.L.; Fockens, P.; Gooszen, H.G.; van Santvoort, H.C. Treatment of Necrotizing Pancreatitis. Clin. Gastroenterol. Hepatol. 2012, 10, 1190-1201. [CrossRef]

11. Stamatakos, M.; Stefanaki, C.; Kontzoglou, K.; Stergiopoulos, S.; Giannopoulos, G.; Safioleas, M. Walled-off Pancreatic Necrosis. World J. Gastroenterol. 2010, 16, 1707-1712. [CrossRef]

12. Van Grinsven, J.; van Brunschot, S.; van Baal, M.C.; Besselink, M.G.; Fockens, P.; van Goor, H.; van Santvoort, H.C.; Bollen, T.L. Natural History of Gas Configurations and Encapsulation in Necrotic Collections During Necrotizing Pancreatitis. J. Gastrointest. Surg. 2018, 22, 1557-1564. [CrossRef]

13. Arvanitakis, M.; Dumonceau, J.M.; Albert, J.; Badaoui, A.; Bali, M.A.; Barthet, M.; Besselink, M.; Deviere, J.; Ferreira, A.O.; Gyökeres, T.; et al. Endoscopic Management of Acute Necrotizing Pancreatitis: European Society of Gastrointestinal Endoscopy (ESGE) Evidence-Based Multidisciplinary Guidelines. Endoscopy 2018, 50, 524-546. [CrossRef]

14. Baron, T.H.; Dimaio, C.J.; Wang, A.Y.; Morgan, K.A. American Gastroenterological Association Clinical Practice Update: Management of Pancreatic Necrosis. Gastroenterology 2020, 158, 67-75. [CrossRef]

15. Brizi, M.G.; Perillo, F.; Cannone, F.; Tuzza, L.; Manfredi, R. The Role of Imaging in Acute Pancreatitis. La Radiologia Medica 2021, 126, 1017-1029. [CrossRef]

16. Gluck, M.; Ross, A.; Irani, S.; Lin, O.; Hauptmann, E.; Siegal, J.; Fotoohi, M.; Crane, R.; Robinson, D.; Kozarek, R.A. Endoscopic and Percutaneous Drainage of Symptomatic Walled-Off Pancreatic Necrosis Reduces Hospital Stay and Radiographic Resources. Clin. Gastroenterol. Hepatol. 2010, 8, 1083-1088. [CrossRef]

17. Van Baal, M.C.; Bollen, T.L.; Bakker, O.J.; van Goor, H.; Boermeester, M.A.; Dejong, C.H.; Gooszen, H.G.; van Der Harst, E.; van Eijck, C.H.; van Santvoort, H.C.; et al. The Role of Routine Fine-Needle Aspiration in the Diagnosis of Infected Necrotizing Pancreatitis. Surgery 2014, 155, 442-448. [CrossRef] [PubMed]

18. Besselink, M.G.H.; Verwer, T.J.; Schoenmaeckers, E.J.P.; Buskens, E.; Ridwan, B.U.; Visser, M.R.; Nieuwenhuijs, V.B.; Gooszen, H.G. Timing of Surgical Intervention in Necrotizing Pancreatitis. Arch Surg. 2007, 142, 1194-1201. [CrossRef] [PubMed]

19. Van Grinsven, J.; van Dijk, S.M.; Dijkgraaf, M.G.; Boermeester, M.A.; Bollen, T.L.; Bruno, M.J.; van Brunschot, S.; Dejong, C.H.; van Eijck, C.H.; van Lienden, K.P.; et al. Postponed or Immediate Drainage of Infected Necrotizing Pancreatitis (POINTER Trial): Study Protocol for a Randomized Controlled Trial. Trials 2019, 20, 1-10. [CrossRef]

20. Besselink, M.G.; van Santvoort, H.C.; Nieuwenhuijs, V.B.; Boermeester, M.A.; Bollen, T.L.; Buskens, E.; Dejong, C.H.; van Eijck, C.H.; van Goor, H.; Hofker, S.S.; et al. Minimally Invasive "step-up Approach" versus Maximal Necrosectomy in Patients with Acute Necrotising Pancreatitis (PANTER Trial): Design and Rationale of a Randomised Controlled Multicenter Trial [ISRCTN13975868]. BMC Surg. 2006, 6, 6. [CrossRef] [PubMed]

21. Van Brunschot, S.; Hollemans, R.A.; Bakker, O.J.; Besselink, M.G.; Baron, T.H.; Beger, H.G.; Boermeester, M.A.; Bollen, T.L.; Bruno, M.J.; Carter, R.; et al. Minimally Invasive and Endoscopic versus Open Necrosectomy for Necrotising Pancreatitis: A Pooled Analysis of Individual Data for 1980 Patients. Gut 2018, 67, 697-706. [CrossRef] [PubMed]

22. van Santvoort, H.C.; Besselink, M.G.; Bakker, O.J.; Hofker, H.S.; Boermeester, M.A.; Dejong, C.H.; van Goor, H.; Schaapherder, A.F.; van Eijck, C.H.; Bollen, T.L.; et al. A Step-up Approach or Open Necrosectomy for Necrotizing Pancreatitis. N. Engl. J. Med. 2010, 362, 108-110. [CrossRef]

23. Seifert, H.; Wehrmann, T.; Schmitt, T.; Zeuzem, S.; Caspary, W.F. Retroperitoneal Endoscopic Debridement for Infected Peripancreatic Necrosis. Lancet 2000, 356, 653-655. [CrossRef] 
24. Seifert, H.; Biermer, M.; Schmitt, W.; Jürgensen, C.; Will, U.; Gerlach, R.; Kreitmair, C.; Meining, A.; Wehrmann, T.; Rösch, T. Transluminal Endoscopic Necrosectomy after Acute Pancreatitis: A Multicentre Study with Long-Term Follow-up (the GEPARD Study). Gut 2009, 58, 1260-1266. [CrossRef] [PubMed]

25. Seewald, S.; Groth, S.; Omar, S.; Imazu, H.; Seitz, U.; de Weerth, A.; Soetikno, R.; Zhong, Y.; Sriram, P.V.J.; Ponnudurai, R.; et al. Aggressive Endoscopic Therapy for Pancreatic Necrosis and Pancreatic Abscess: A New Safe and Effective Treatment Algorithm (Videos). Gastrointest. Endosc. 2005, 62, 92-100. [CrossRef]

26. Voermans, R.P.; Veldkamp, M.C.; Rauws, E.A.; Bruno, M.J.; Fockens, P. Endoscopic Transmural Debridement of Symptomatic Organized Pancreatic Necrosis. Gastrointest. Endosc. 2007, 66, 909-916. [CrossRef] [PubMed]

27. Charnley, R.M.; Lochan, R.; Gray, H.; O’Sullivan, C.B.; Scott, J.; Oppong, K.E.N.W. Endoscopic Necrosectomy as Primary Therapy in the Management of Infected Pancreatic Necrosis. Endoscopy 2006, 38, 925-928. [CrossRef]

28. Escourrou, J.; Shehab, H.; Buscail, L.; Bournet, B.; Andrau, P.; Moreau, J.; Fourtanier, G. Peroral Transgastric/Transduodenal Necrosectomy Success in the Treatment of Infected Pancreatic Necrosis. Ann. Surg. 2008, 248, 1074-1080. [CrossRef]

29. Gardner, T.B.; Coelho-Prabhu, N.; Gordon, S.R.; Gelrud, A.; Maple, J.T.; Papachristou, G.I.; Freeman, M.L.; Topazian, M.D.; Attam, R.; MacKenzie, T.A.; et al. Direct Endoscopic Necrosectomy for the Treatment of Walled-off Pancreatic Necrosis: Results from a Multicenter, U.S. Series. Gastrointest. Endosc. 2011, 73, 718-726. [CrossRef]

30. Bakker, O.J.; van Santvoort, H.C.; van Brunschot, S.; Geskus, R.B.; Besselink, M.G.; Bollen, T.L.; van Eijck, C.H.; Fockens, P.; Hazebroek, E.J.; Nijmeijer, R.M.; et al. Endoscopic Transgastric vs Surgical Necrosectomy for Infected Necrotizing Pancreatitis: A Randomized Trial. JAMA-J. Am. Med. Assoc. 2012, 307, 1053-1061. [CrossRef]

31. Van Brunschot, S.; van Grinsven, J.; van Santvoort, H.C.; Bakker, O.J.; Besselink, M.G.; Boermeester, M.A.; Bollen, T.L.; Bosscha, K.; Bouwense, S.A.; Bruno, M.J.; et al. Endoscopic or Surgical Step-up Approach for Infected Necrotising Pancreatitis: A Multicentre Randomised Trial. Lancet 2018, 391, 51-58. [CrossRef]

32. Bang, J.Y.; Wilcox, C.M.; Arnoletti, J.P.; Varadarajulu, S. Superiority of Endoscopic Interventions over Minimally Invasive Surgery for Infected Necrotizing Pancreatitis: Meta-Analysis of Randomized Trials. Dig. Endosc. 2020, 32, 298-308. [CrossRef] [PubMed]

33. Haney, C.M.; Kowalewski, K.F.; Schmidt, M.W.; Koschny, R.; Felinska, E.A.; Kalkum, E.; Probst, P.; Diener, M.K.; Müller-Stich, B.P.; Hackert, T.; et al. Endoscopic versus Surgical Treatment for Infected Necrotizing Pancreatitis: A Systematic Review and Meta-Analysis of Randomized Controlled Trials. Surg. Endoscopy 2020, 34, 2429-2444. [CrossRef] [PubMed]

34. Bang, J.Y.; Arnoletti, J.P.; Holt, B.A.; Sutton, B.; Hasan, M.K.; Navaneethan, U.; Feranec, N.; Wilcox, C.M.; Tharian, B.; Hawes, R.H.; et al. An Endoscopic Transluminal Approach, Compared With Minimally Invasive Surgery, Reduces Complications and Costs for Patients With Necrotizing Pancreatitis. Gastroenterology 2019, 156, 1027-1040. [CrossRef]

35. Khan, M.A.; Kahaleh, M.; Khan, Z.; Tyberg, A.; Solanki, S.; Haq, K.F.; Sofi, A.; Lee, W.M.; Ismail, M.K.; Tombazzi, C.; et al. Time for a Changing of Guard From Minimally Invasive Surgery to Endoscopic Drainage for Management of Pancreatic Walled-off Necrosis. J. Clin. Gastroenterol. 2019, 53, 81-88. [CrossRef]

36. Varadarajulu, S.; Phadnis, M.A.; Christein, J.D.; Wilcox, C.M. Multiple Transluminal Gateway Technique for EUS-Guided Drainage of Symptomatic Walled-off Pancreatic Necrosis. Gastrointest. Endosc. 2011, 74, 74-80. [CrossRef]

37. Abu Dayyeh, B.K.; Mukewar, S.; Majumder, S.; Zaghlol, R.; Vargas Valls, E.J.; Bazerbachi, F.; Levy, M.J.; Baron, T.H.; Gostout, C.J.; Petersen, B.T.; et al. Large-Caliber Metal Stents versus Plastic Stents for the Management of Pancreatic Walled-off Necrosis. Gastrointest. Endosc. 2018, 87, 141-149. [CrossRef]

38. Sarkaria, S.; Sethi, A.; Rondon, C.; Lieberman, M.; Srinivasan, I.; Weaver, K.; Turner, B.G.; Sundararajan, S.; Berlin, D.; Gaidhane, M.; et al. Pancreatic Necrosectomy Using Covered Esophageal Stents: A Novel Approach. J. Clin. Gastroenterol. 2014, 48, 145-152. [CrossRef]

39. Vinay Chandrasekhara, A.; Barthet, M.; Devière, J.; Bazerbachi, F.; Lakhtakia, S.; Easler, J.J.; Peetermans, J.A.; McMullen, E.; Gjata, O.; Gourlay, M.L.; et al. Safety and Efficacy of Lumen-Apposing Metal Stents versus Plastic Stents to Treat Walled-off Pancreatic Necrosis: Systematic Review and Meta-Analysis. Endosc. Int. Open 2020, 08, E1639-E1653. [CrossRef]

40. Antillon, M.R.; Bechtold, M.L.; Bartalos, C.R.; Marshall, J.B. Transgastric Endoscopic Necrosectomy with Temporary Metallic Esophageal Stent Placement for the Treatment of Infected Pancreatic Necrosis (with Video). Gastrointest. Endosc. 2009, 69, 178-180. [CrossRef]

41. Dorrell, R.; Pawa, S.; Pawa, R. Endoscopic Management of Pancreatic Fluid Collections. J. Clin. Med. 2021, 10, 284. [CrossRef]

42. Binmoeller, K.F.; Shah, J. A Novel Lumen-Apposing Stent for Transluminal Drainage of Nonadherent Extraintestinal Fluid Collections. Endoscopy 2011, 43, 337-342. [CrossRef]

43. Sharaiha, R.Z.; Tyberg, A.; Khashab, M.A.; Kumta, N.A.; Karia, K.; Nieto, J.; Siddiqui, U.D.; Waxman, I.; Joshi, V.; Benias, P.C.; et al. Endoscopic Therapy With Lumen-Apposing Metal Stents Is Safe and Effective for Patients With Pancreatic Walled-off Necrosis. Clin. Gastroenterol. Hepatol. 2016, 14, 1797-1803. [CrossRef]

44. Parsa, N.; Nieto, J.M.; Powers, P.; Mitsuhashi, S.; Abdelqader, A.; Hadzinakos, G.; Anderloni, A.A.; Fugazza, A.; James, T.W.; Arlt, A.; et al. Endoscopic Ultrasound-Guided Drainage of Pancreatic Walled-off Necrosis Using 20-Mm versus 15-Mm Lumen-Apposing Metal Stents: An International, Multicenter, Case-Matched Study. Endoscopy 2020, 52, 211-219. [CrossRef]

45. Anderloni, A.; di Leo, M.; Carrara, S.; Fugazza, A.; Maselli, R.; Buda, A.; Amato, A.; Auriemma, F.; Repici, A. Endoscopic Ultrasound-Guided Transmural Drainage by Cautery-Tipped Lumen-Apposing Metal Stent: Exploring the Possible Indications. Ann. Gastroenterol. 2018, 31, 735. [CrossRef] [PubMed] 
46. Mussetto, A.; Fugazza, A.; Fuccio, L.; Triossi, O.; Repici, A.; Anderloni, A. Current Uses and Outcomes of Lumen-Apposing Metal Stents. Ann. Gastroenterol. 2018, 31, 535. [CrossRef]

47. Tarantino, I.; Ligresti, D.; Tuzzolino, F.; Barresi, L.; Curcio, G.; Granata, A.; Traina, M. Clinical Impact of EUS Treatment of Walled-off Pancreatic Necrosis with Dedicated Devices. Endosc. Int. Open 2017, 5, E784-E791. [CrossRef] [PubMed]

48. Bekkali, N.; Nayar, M.; Leeds, J.; Charnley, R.; Huggett, M.; Oppong, K. A Comparison of Outcomes between a Lumen-Apposing Metal Stent with Electrocautery-Enhanced Delivery System and a Bi-Flanged Metal Stent for Drainage of Walled-off Pancreatic Necrosis. Endosc. Int. Open 2017, 5, E1189-E1196. [CrossRef] [PubMed]

49. Anderloni, A.; Fabbri, C.; Nieto, J.; Uwe, W.; Dollhopf, M.; Aparicio, J.R.; Perez-Miranda, M.; Tarantino, I.; Arlt, A.; Vleggaar, F.; et al. The Safety and Efficacy of a New 20-Mm Lumen Apposing Metal Stent (Lams) for the Endoscopic Treatment of Pancreatic and Peripancreatic Fluid Collections: A Large International, Multicenter Study. Surg. Endosc. 2021, 35, 1741-1748. [CrossRef]

50. Binda, C.; Dabizzi, E.; Anderloni, A.; Cennamo, V.; Fiscaletti, M.; Fugazza, A.; Jovine, E.; Ercolani, G.; Gasbarrini, A.; Fabbri, C. Single-Step Endoscopic Ultrasound-Guided Multiple Gateway Drainage of Complex Walled-off Necrosis with Lumen Apposing Metal Stents. Eur. J. Gastroenterol. Hepatol. 2020, 32, 1401-1404. [CrossRef]

51. Bang, J.Y.; Hasan, M.; Navaneethan, U.; Hawes, R.; Varadarajulu, S. Lumen-Apposing Metal Stents (LAMS) for Pancreatic Fluid Collection (PFC) Drainage: May Not Be Business as Usual. Gut 2017, 66, 2054-2056. [CrossRef]

52. Fugazza, A.; Colombo, M.; Gabbiadini, R.; Carrara, S.; Maselli, R.; Anderloni, A.; Repici, A. Repositioning Rather than Replacing: The Management of a Dislodged Lumen-Apposing Metal Stent in a Walled off Necrosis. Am. J. Gastroenterol. 2020, 115, 811. [CrossRef] [PubMed]

53. Dhir, V.; Adler, D.G.; Dalal, A.; Aherrao, N.; Shah, R.; Maydeo, A. Early Removal of Biflanged Metal Stents in the Management of Pancreatic Walled-off Necrosis: A Prospective Study. Endoscopy 2018, 50, 597-605. [CrossRef] [PubMed]

54. Fugazza, A.; Sethi, A.; Trindade, A.J.; Troncone, E.; Devlin, J.; Khashab, M.A.; Vleggaar, F.P.; Bogte, A.; Tarantino, I.; Deprez, P.H.; et al. International Multicenter Comprehensive Analysis of Adverse Events Associated with Lumen-Apposing Metal Stent Placement for Pancreatic Fluid Collection Drainage. Gastrointest. Endosc. 2020, 91, 574-583. [CrossRef]

55. Chen, Y.I.; Barkun, A.N.; Adam, V.; Bai, G.; Singh, V.K.; Bukhari, M.; Gutierrez, O.B.; Elmunzer, B.J.; Moran, R.; Fayad, L.; et al. Cost-Effectiveness Analysis Comparing Lumen-Apposing Metal Stents with Plastic Stents in the Management of Pancreatic Walled-off Necrosis. Gastrointest. Endosc. 2018, 88, 267-276. [CrossRef]

56. Liu, F.; Wu, L.; Wang, X.D.; Xiao, J.G.; Li, W. Endoscopic Gastric Fenestration of Debriding Pancreatic Walled-off Necrosis: A Pilot Study. World J. Gastroenterol. 2020, 26, 6431-6441. [CrossRef] [PubMed]

57. Albers, D.; Meining, A.; Hann, A.; Ayoub, Y.K.; Schumacher, B. Direct Endoscopic Necrosectomy in Infected Pancreatic Necrosis Using Lumen-Apposing Metal Stents: Early Intervention Does Not Compromise Outcome. Endosc. Int. Open 2021, 9, E490-E495. [CrossRef] [PubMed]

58. Yan, L.; Dargan, A.; Nieto, J.; Shariaha, R.Z.; Binmoeller, K.F.; Adler, D.G.; Desimone, M.; Berzin, T.; Swahney, M.; Draganov, P.V.; et al. Direct Endoscopic Necrosectomy at the Time of Transmural Stent Placement Results in Earlier Resolution of Complex Walled-off Pancreatic Necrosis: Results from a Large Multicenter United States Trial. Endosc. Ultrasound 2019, 8, 172-179. [CrossRef]

59. Grimm, H.; Binmoeller, K.F.; Soehendra, N. Endosonography-Guided Drainage of a Pancreatic Pseudocyst. Gastrointest. Endosc. 1992, 38, 170-171. [CrossRef]

60. Anderloni, A.; Attili, F.; Carrara, S.; Galasso, D.; di Leo, M.; Costamagna, G.; Repici, A.; Kunda, R.; Larghi, A. Intra-Channel Stent Release Technique for Fluoroless Endoscopic Ultrasound-Guided Lumen-Apposing Metal Stent Placement: Changing the Paradigm. Endosc. Int. Open 2017, 5, E25-E29. [CrossRef]

61. Yasuda, I.; Nakashima, M.; Iwai, T.; Isayama, H.; Itoi, T.; Hisai, H.; Inoue, H.; Kato, H.; Kanno, A.; Kubota, K.; et al. Japanese Multicenter Experience of Endoscopic Necrosectomy for Infected Walled-off Pancreatic Necrosis: The JENIPaN Study. Endoscopy 2013, 45, 627-634. [CrossRef]

62. Guo, J.; Saftoiu, A.; Vilmann, P.; Fusaroli, P.; Giovannini, M.; Mishra, G.; Rana, S.S.; Ho, S.; Poley, J.-W.; Leong Ang, T.; et al. A Multi-Institutional Consensus on How to Perform Endoscopic Ultrasound-Guided Peri-Pancreatic Fluid Collection Drainage and Endoscopic Necrosectomy. Endosc. Ultrasound 2017, 6, 285-291. [CrossRef]

63. Schmidt, P.N.; Novovic, S.; Roug, S.; Feldager, E. Endoscopic, Transmural Drainage and Necrosectomy for Walled-off Pancreatic and Peripancreatic Necrosis Is Associated with Low Mortality-A Single-Center Experience. Scand. J. Gastroenterol. 2015, 50, 611-618. [CrossRef]

64. Xiao, N.-J.; Cui, T.-T.; Liu, F.; Li, W. Current Status of Treatments of Pancreatic and Peripancreatic Collections of Acute Pancreatitis. World J. Gastrointest. Surg. 2021, 13, 633-644. [CrossRef] [PubMed]

65. Van Der Wiel, S.E.; Poley, J.W.; Grubben, M.J.A.L.; Bruno, M.J.; Koch, A.D. The EndoRotor, a Novel Tool for the Endoscopic Management of Pancreatic Necrosis. Endoscopy 2018, 50, E240-E241. [CrossRef]

66. Hollerbach, S.; Wellmann, A.; Meier, P.; Ryan, J.; Franco, R.; Koehler, P. The EndoRotor ${ }^{\circledR}$ : Endoscopic Mucosal Resection System for Non-Thermal and Rapid Removal of Esophageal, Gastric, and Colonic Lesions: Initial Experience in Live Animals. Endosc. Int. Open 2016, 4, E475-E479. [CrossRef] [PubMed]

67. Van der Wiel, S.E.; May, A.; Poley, J.W.; Grubben, M.J.A.L.; Wetzka, J.; Bruno, M.J.; Koch, A.D. Preliminary Report on the Safety and Utility of a Novel Automated Mechanical Endoscopic Tissue Resection Tool for Endoscopic Necrosectomy: A Case Series. Endosc. Int. Open 2020, 8, E274-E280. [CrossRef] 
68. Larghi, A.; Rizzatti, G.; Rimbaș, M.; Impagnatiello, M.; Gasbarrini, A.; Costamagna, G. Endorotor-Based Endoscopic Necrosectomy as a Rescue or Primary Treatment of Complicated Walled-off Pancreatic Necrosis. A Case Series. J. Gastrointestin. Liver. Dis. 2020, 29, 681-684. [CrossRef]

69. Stassen, P.M.C.; de Jonge, P.J.F.; Bruno, M.J.; Koch, A.D.; Trindade, A.J.; Benias, P.C.; Sejpal, D.V.; Siddiqui, U.D.; Chapman, C.G.; Villa, E.; et al. Safety and Efficacy of a Novel Resection System for Direct Endoscopic Necrosectomy of Walled-off Pancreas Necrosis: A Prospective, International, Multicenter Trial. Gastrointest. Endosc. 2021, in press. [CrossRef]

70. Siddiqui, A.A.; Easler, J.; Strongin, A.; Slivka, A.; Kowalski, T.E.; Muddana, V.; Chennat, J.; Baron, T.H.; Loren, D.E.; Papachristou, G.I. Hydrogen Peroxide-Assisted Endoscopic Necrosectomy for Walled-off Pancreatic Necrosis: A Dual Center Pilot Experience. Dig. Dis. Sci. 2014, 59, 687-690. [CrossRef]

71. Garg, R.; Gupta, S.; Singh, A.; Simonson, M.T.; Rustagi, T.; Chahal, P. Hydrogen Peroxide Assisted Endoscopic Necrosectomy for Walled-off Pancreatic Necrosis: A Systematic Review and Meta-Analysis. Pancreatology 2021, 21, 1540-1547. [CrossRef] [PubMed]

72. Günay, S.; Paköz, B.; Çekiç, C.; Çamyar, H.; Alper, E.; Yüksel, E.S.; Topal, F.; Binicier, Ö.B. Evaluation of Hydrogen PeroxideAssisted Endoscopic Ultrasonography-Guided Necrosectomy in Walled-off Pancreatic Necrosis: A Single-Center Experience. Medicine 2021, 100, e23175. [CrossRef] [PubMed]

73. Abdelhafez, M.; Elnegouly, M.; Hasab Allah, M.S.; Elshazli, M.; Mikhail, H.M.S.; Yosry, A. Transluminal Retroperitoneal Endoscopic Necrosectomy with the Use of Hydrogen Peroxide and without External Irrigation: A Novel Approach for the Treatment of Walled-off Pancreatic Necrosis. Surg. Endosc. 2013, 27, 3911-3920. [CrossRef]

74. Messallam, A.A.; Adler, D.G.; Shah, R.J.; Nieto, J.M.; Moran, R.; Elmunzer, B.J.; Cosgrove, N.; Mullady, D.; Singh, H.; Cote, G.; et al. Direct Endoscopic Necrosectomy With and Without Hydrogen Peroxide for Walled-off Pancreatic Necrosis: A Multicenter Comparative Study. Am. J. Gastroenterol. 2021, 116, 700-709. [CrossRef] [PubMed]

75. DiBianco, J.M.; Lange, J.; Heidenberg, D.; Mufarrij, P. Oxygen Venous Embolism After Hydrogen Peroxide Use During Percutaneous Nephrolithotomy. J. Endourol. Case Rep. 2019, 5, 25. [CrossRef]

76. Peng, Z.; Li, H.; Cao, Z.; Zhang, W.; Li, H.; Dai, R.; Liu, L.; Mao, X.; George, D.M.; Huang, T. Oxygen Embolism after Hydrogen Peroxide Irrigation during Hip Arthroscopy: A Case Report. BMC Musculoskelet. Disord. 2020, 21, 1-6. [CrossRef]

77. Zhang, J.; Zhang, C.; Yan, J. Massive Cerebral Gas Embolism under Discectomy Due to Hydrogen Peroxide Irrigation. Case Rep. Neurol. Med. 2015, 2015, 1-4. [CrossRef]

78. Tsai, S.K.; Lee, T.Y.; Mok, M.S. Gas Embolism Produced by Hydrogen Peroxide Irrigation of an Anal Fistula during Anesthesia. Anesthesiology 1985, 63, 316-317. [CrossRef]

79. Jones, P.M.; Segal, S.H.; Gelb, A.W. Venous Oxygen Embolism Produced by Injection of Hydrogen Peroxide into an Enterocutaneous Fistula. Anesth. Analg. 2004, 99, 1861-1863. [CrossRef]

80. Haller, G.; Faltin-Traub, E.; Faltin, D.; Kern, C. Oxygen Embolism after Hydrogen Peroxide Irrigation of a Vulvar Abscess. Br. J. Anaesth. 2002, 88, 597-599. [CrossRef]

81. Akuji, M.A.; Chambers, D.J. Hydrogen Peroxide: More Harm than Good? Br. J. Anaesth. 2017, 118, 958-959. [CrossRef] [PubMed]

82. Zhao, S.L.; Zhang, X.Y.; Xiao, Y.; Mo, X.Y.; Chen, Z.P.; Lin, W.; Huang, Z.F.; Chen, B.L. Gas Embolism After Hydrogen Peroxide Use During Spine Surgery: Case Report and Literature Review. World Neurosurg. 2020, 143, 228-231. [CrossRef]

83. Loske, G.; Schorsch, T.; Gobrecht, O.; Martens, E.; Rucktäschel, F. Transgastric Endoscopic Vacuum Therapy with a New Open-Pore Film Drainage Device in a Case of Infective Pancreatic Necrosis. Endoscopy 2016, 48, E148-E149. [CrossRef]

84. Wallstabe, I.; Tiedemann, A.; Schiefke, I. Endoscopic Vacuum-Assisted Therapy of Infected Pancreatic Pseudocyst Using a Coated Sponge. Endoscopy 2012, 44 (Suppl. S2), E49-E50. [CrossRef]

85. Wedemeyer, J.; Kubicka, S.; Lankisch, T.O.; Wirth, T.; Patecki, M.; Hiss, M.; Manns, M.P.; Schneider, A.S. Transgastrically Placed Endoscopic Vacuum-Assisted Closure System as an Addition to Transgastric Necrosectomy in Necrotizing Pancreatitis (with Video). Gastrointest. Endosc. 2012, 76, 1238-1241. [CrossRef]

86. Fähndrich, M.; Sandmann, M. A New Method for Endoscopic Drainage of Pancreatic Necrosis through a Gastrostomy Site Using an Endosponge. Endoscopy 2014, 46, E459. [CrossRef] [PubMed]

87. Wallstabe, I.; Tiedemann, A.; Schiefke, I. Endoscopic Vacuum-Assisted Therapy of an Infected Pancreatic Pseudocyst. Endoscopy 2011, 43, E312-E313. [CrossRef] [PubMed]

88. Scherer, S.S.; Pietramaggiori, G.; Mathews, J.C.; Prsa, M.J.; Huang, S.; Orgill, D.P. The Mechanism of Action of the Vacuum-Assisted Closure Device. Plast. Reconstr. Surg. 2008, 122, 786-797. [CrossRef]

89. Fernandez-Del Castillo, C.; Rattner, D.W.; Makary, M.A.; Mostafavi, A.; Mcgrath, D.; Warshaw, A.L. Debridement and Closed Packing for the Treatment of Necrotizing Pancreatitis; Lippincott Williams \& Wilins: Philadelphia, PE, USA, 1998 ; Volume 228.

90. De Beaux, A.C.; Palmer, K.R.; Carter, D.C. Factors Influencing Morbidity and Mortality in Acute Pancreatitis; an Analysis of 279 Cases. Gut 1995, 37, 12-13. [CrossRef]

91. Rodriguez, J.R.; Razo, A.O.; Targarona, J.; Thayer, S.P.; Rattner, D.W.; Warshaw, A.L.; Castillo, C.F. Debridement and Closed Packing for Sterile or Infected Necrotizing Pancreatitis: Insights into Indications and Outcomes in 167 Patients. Ann. Surg. 2008, 247, 294. [CrossRef]

92. Trikudanathan, G.; Tawfik, P.; Amateau, S.K.; Mbbs, S.M.; Arain, M.; Attam, R.; Beilman, G.; Flanagan, S.; Freeman, M.L.; Mallery, S. Early ( $<4$ Weeks) Versus Standard $(\geq 4$ Weeks) Endoscopically Centered Step-Up Interventions for Necrotizing Pancreatitis. Am. J. Gastroenterol. 2018, 113, 1550-1558. [CrossRef] [PubMed] 
93. Van Grinsven, J.; van Brunschot, S.; Fockens, P.; van Grinsven, J.; Bakker, O.J.; van Santvoort, H.C.; Bollen, T.L.; Boermeester, M.A.; van Santvoort, H.C.; Besselink, M.G.; et al. Diagnostic Strategy and Timing of Intervention in Infected Necrotizing Pancreatitis: An International Expert Survey and Case Vignette Study. Hpb 2016, 18, 49-56. [CrossRef] [PubMed]

94. Bang, J.Y.; Wilcox, C.M.; Arnoletti, J.P.; Peter, S.; Christein, J.; Navaneethan, U.; Hawes, R.; Varadarajulu, S. Validation of the Orlando Protocol for Endoscopic Management of Pancreatic Fluid Collections in the Era of Lumen-Apposing Metal Stents. Dig. Endosc. 2021. Epub ahead of print. [CrossRef] [PubMed]

95. Bruno, M. Conventional Endoscopic Techniques Versus EndoRotor ${ }^{\circledR}$ System for Necrosectomy of Walled of Necrosis (RESOIVE). Natl. Libr. Med.. Identifier: NCT04814693, in press. 